\title{
Estimation of the Intrazonal Travel Time of Different Modes for the Home-Based School Trips Using Regression Model
}

\author{
Yavuz Delice $^{1 *}$, Halit Özen ${ }^{2}$, and Ehsan Amirnazmiafshar ${ }^{3}$ \\ ${ }^{1}$ Yalova University, Department of Transportation Engineering, Faculty of Engineering, Yalova, \\ 77200,Turkey. \\ ${ }^{2}$ Yildiz Technical University, Department of Civil Engineering, Faculty of Civil Engineering, \\ Istanbul, 34220, Turkey. \\ ${ }^{3}$ Istanbul Technical University, Department of Transportation Engineering, Faculty of Civil \\ Engineering, Istanbul, 34469, Turkey.
}

\begin{tabular}{l} 
ARTICLE INFO \\
\hline Keywords: \\
Intrazonal trips, travel \\
time, home-based school \\
trips, regression mode.
\end{tabular}

\section{Introduction}

Sometimes, data related to the features of travel distribution patterns and street network are not easily accessible to explicate the trips in cities. For instance, average intrazonal travel time in cities affected by the characteristics of trips; environment and user profile which are not available to 
urban planners. The intrazonal trips do not exist in the network of centroid-to-centroid travel, so they are not considered in the model estimation. Intrazonal travels are localized and short duration trips, which are within a transportation analysis zone (TAZ) of a model. For intrazonal trips production, the zone needs to have production and attraction units. Majority of studies mostly focused on the interzonal trips to estimate the travel distance or time between the zones but intrazonal travel time is not investigated enough to find the accurate method for estimating the travel time of trips in the zone precisely, and it is still an ongoing challenge in spatial models.

The features of the level of service are missing for all intrazonal trips that this is a problem, which leads to missing the data. Intrazonal travel time estimation conducive to having the better representation of the population under study obtained from the resulting sample and prevent to bias the model calibration. In this study, the household survey of Denizli city in Turkey with more than 13000 participants and 214 zones is used for the average intrazonal travel time approximation of walking and transport publication modes on home-based school trips in a medium-sized city based on the date of origin and destination travels.

The rest of the paper including as follows. In section 2, there are the reviews the pas studies related to the subject. The information about the data is explained in Section 3. The methodology part is presented in section 4. The results and discussion of them are included in Section 5. The study is concluded in Section 6.

\section{The current state of knowledge}

One of the significant issues for the development of the city is mobility. In the literature, some studies focused on the effect of environment on travel behavior (Daganzo 1984; da Silva, Costa, and Brondino 2007; Angel, Parent, and Civco 2010; Khan, Kockelman, and Xiong 2014). In intrazonal trips, one of the most important factors that influence the mode choice is physical features of the zone. Greenwald (2006) indicated that the urban form has the impact on the regional distribution of travel and mode choice. According to Bhatta and Larsen (2011), because of the short travel distance in intrazonal trips, passengers prefer to use non-motorized modes such as walking or cycling.Moreover, their study designated that the intrazonal trips cannot be ignored because they effect on the pollution and congestion at a local level. Especially, when the trips are not concentrated around the zone centroid, the estimation of parameters can be biased. Ortúzar and Willumsen (2011) suggested that the intrazonal trips can be eliminated from the model process unless if they can be estimated from the simple methods.

There are some methods in the last studies to estimate the average distance on intrazonal trips. The U.S. Department of Commerce (1965) suggested that the average intrazonal trip distance could be equivalent to the average distance between the centroid of a zone and the centroids of adjacent zones divided by two that is half the distance between the centroid of the zone and the centroid of the closest zone. Venigalla et al. (1999) indicated that it could be equal to half the distance between the centroid of the closest zone and the centroid of the zone. In a study by Smeed (1967), an equation was proposed based on actual grid-shaped street networks showed that the average intrazonal trips are only deepened on the area of the zone. Batty (1976) found the equation to find the intrazonal trip distance which was related to the radius and area of the zone. Fotheringham proposed equations, which were, depends on the distance between the centroids of adjacent zones and radius of the zone.

Kordi et al. (2012) by scattering the origins and destinations of the flows within their zones developed a new approach to estimate the average trip distance. This method gave a better model fit with smaller errors. In a study by Plaza and Silva (2015), it is found that the average intrazonal trip distance has the high correlation with area and perimeter of the zone. None of these studies 
focuses on the particular factor for each mode. The aim of this study is finding the most important factor that affects the intrazonal travel time of walking and public transport separately. Moreover, finding the related factor related to the intrazonal travel time when all trip modes including walking, public transport, private vehicle, and subscription bus are considered.

\section{Data}

Some factors have the important influence on the average intrazonal travel time that was mentioned in the literature such as urban form, road infrastructure and distribution of land uses. For instance, the area, perimeter, shape factor of each study area, the circular shape factor of each study area, street density are focused in the studies (Costa 1992; Plaza and Silva 2015). In this study, the household survey, which contains more than 13000 households of Denizli city, is conducted. Moreover, there are 208 zones in Denizli city including urban, suburban and rural area are focused on finding the accurate results for average intrazonal travel time in a Denizli city, which is a medium-sized city. The geometrical factors, related to the average intrazonal travel time obtained from PTV Visum which is a macro-simulation model, are shown in Table 1.

Table 1 The factors associated with the average intrazonal travel time.

\begin{tabular}{|l|l|}
\hline Factors & Unit \\
\hline Area & $\mathrm{Km}^{2}$ \\
\hline perimeter & $\mathrm{Km}$ \\
\hline Number of stop point density & Number/ $\mathrm{Km}^{2}$ \\
\hline Length & $\mathrm{Km}$ \\
\hline Length density & Number/Km \\
\hline Number of stop point over the length & Number/Km \\
\hline Number of nodes & Number \\
\hline Number of links & Number \\
\hline Population & People \\
\hline Population density & People/Km \\
\hline
\end{tabular}

The data analysis shows that on the home-based school trips, 56 percent of travels are intrazonal trips, which include a large share of all trips. In intrazonal trips on home-based school travels, 75 percent of passengers choose the walking mode, which indicates, that the majority of passengers prefer to choose the walking mode for intrazonal trips. In this study, two different modes including walking and public transport are studied. The number of the Traffic Analysis Zones (TAZs) to find the average intrazonal travel time for walking mode is 58 and for public transport is 23 . Some factors related to the intrazonal travel time in the zone are analyzed. These factors are analyzed for different mode separately for walking mode, public transport, and all trip modes together.

\section{Methods}

In this study, the regression model develops the procedure to estimate the intrazonal travel time for walking mode, public transport and all trip modes in a metropolitan city. The regression-based analyses are one the most employed statistical methods throughout the research work (Turner 2013).

Table 2 presents the correlation between the average intrazonal travel time and each related factor for all trip modes. 
Table 2 The correlation between related factors and average intrazonal travel time of all trip modes.

\begin{tabular}{|l|l|}
\hline Related factors & Average intrazonal travel time (Min) \\
\hline Area $\left(\mathrm{km}^{2}\right)$ & 0.498 \\
\hline Number of stop point (number) & -0.128 \\
\hline Perimeter $(\mathrm{km})$ & 0.453 \\
\hline Population density (people/ $\left.\mathrm{km}^{2}\right)$ & -0.363 \\
\hline Number of links (number) & -0.231 \\
\hline Number of nodes (number) & -0.226 \\
\hline Population (people) & -0.510 \\
\hline The total length of the network $(\mathrm{km})$ & 0.001 \\
\hline Number of stop points over length (number/km) & -0.253 \\
\hline Length density $(1 / \mathrm{km})$ & -0.424 \\
\hline Stop point density $\left(\mathrm{number} / \mathrm{km}^{2}\right)$ & -0.278 \\
\hline Number of the student in the zone (number) & -0.140 \\
\hline Average family income in the zone (Turkish lira) & -0.069 \\
\hline
\end{tabular}

In home-based school trips, some factors have the positive correlation with average intrazonal travel time, which means when these factors are raised; the intrazonal trip time will increase. For instance, as much as the area, perimeter and the total length of the network in the zone is more; the intrazonal travel time is higher because the distance may increase in the bigger zones. Besides, when the total length of the network is longer, the intrazonal travel time in the zone is higher. The higher average income rate in the zone increases the likelihood of using the private vehicle in the zone. It can be an important factor, which causes to reduce the average travel time in the zone. On the other hand, some factors have the adverse correlation with average travel time in the zone. When the zone has more stop point, number of links and nodes, number of stop point over length, length density and stop point density, it leads to decreasing the intrazonal travel time in the zone by increasing the accessibility to the public transport. Furthermore, when the population, population density, the number of student in the zone increases, the intrazonal travel time increases, the number of schools in the city will increase, and the distance between schools and home will be less, which leads to having less intrazonal travel time.

Table 3 depict the correlation between the average intrazonal travel time and each related factor for walking mode. 
Table 3 The correlation between related factors and average intrazonal travel time of walking mode.

\begin{tabular}{|l|l|}
\hline Related factors & Average intrazoanl travel time (min) \\
\hline Area $\left(\mathrm{km}^{2}\right)$ & 0.491 \\
\hline Perimeter $(\mathrm{km})$ & 0.559 \\
\hline Population density $\left(\right.$ people $\left./ \mathrm{km}^{2}\right)$ & -0.574 \\
\hline Number of links in the network (number) & -0.040 \\
\hline Number of nodes in the network (number) & -0.022 \\
\hline Population (people) & -0.328 \\
\hline The total length of the network $(\mathrm{km})$ & 0.255 \\
\hline Number of stop points over length $($ number $/ \mathrm{km})$ & -0.014 \\
\hline
\end{tabular}

The area, perimeter, total length of the network are the factors that have a positive correlation with intrazonal travel time. Because when they increase, the distance between home and school can increase which rise the average intrazonal travel time of walking mode on home-based school trips. When the number of links, nodes, stop points over length increase, because of increasing the ability to access to the public transport, decrease the intrazonal travel time of walking to the school indirectly. When the population and, especially population density increase, the number of schools may increase that reduces the intrazonal travel time between home and school.

Table 4 shows the correlation between the average intrazonal travel time and each related factor for public transport mode.

Table 4 The correlation between related factors and average intrazonal travel time of public transport mode.

\begin{tabular}{|l|l|}
\hline Related factors & Correlation value \\
\hline Number of stop point in the network (number) & -0.469 \\
\hline Number of links in the network (number) & -0.538 \\
\hline Number of nodes in the network (number) & -0.523 \\
\hline Number of stop points over the length in the network (number/km) & -0.112 \\
\hline
\end{tabular}

Some factors by increasing the access to the public transport led to reducing the average intrazonal travel time for home-based school trips in the zone including increasing the number of stop point, links, modes, stop point over the length in the network in the zone.

\section{Results}

The analyzing of the correlation between the average intrazonal travel time and different related factors designates that the population factor for all trip modes modes, population density factor for walking mode and the number of links for public transport has the highest correlation with intrazonal travel time. Because of being a high correlation among the factors, they cannot be included in the model. Table 5 shows the factor considered as an independent variable in each model. 
Table 5 The selected independent variable for each estimated model of intrazonal travel time.

\begin{tabular}{|l|l|}
\hline Independent variable & Selected independent variable \\
\hline All trip modes & Population \\
\hline Walking & Population density \\
\hline Public transport & Number of links \\
\hline
\end{tabular}

Table 5, presents that the logarithmic trend line for all trip modes model and the polynomial trend line for walking and public transport provide the best fit and produce the best adjustment regarding the higher R2 compared to the other trend line including exponential, linear and power trend lines as shown in Table 6.

Table 6 The $\mathrm{R}^{2}$ of different trend lines for each estimated models of intrazonal travel time.

\begin{tabular}{|l|l|l|l|l|l|}
\hline \multirow{2}{*}{ Model } & \multicolumn{4}{|l}{$\mathbf{R}^{2}$ of trend line } & \multicolumn{4}{l|}{} \\
\cline { 2 - 6 } & Exponential & Linear & Logarithmic & Polynomial & Power \\
\hline All trip modes & 0.223 & 0.253 & 0.415 & 0.371 & 0.353 \\
\hline Walking & 0.279 & 0.319 & 0.385 & 0.459 & 0.348 \\
\hline Public transport & 0.191 & 0.256 & 0.376 & 0.410 & 0.272 \\
\hline
\end{tabular}

By regarding the selected factor and the trend line for each model, the best-obtained equation and type of its trend line for each mode that $\mathrm{Y}$ is the estimated intrazonal travel time and $\mathrm{x}$ is the related independent variable for each mode are shown in table 7.

Table 7 The equation and type of trend line of the selected trend line for each estimated model of intrazonal travel time.

\begin{tabular}{|l|c|l|}
\hline \multirow{2}{*}{ Model } & \multicolumn{2}{|l|}{ Selected trend line } \\
\cline { 2 - 3 } & Equation & Type of trend line \\
\hline All trip Modes & $\mathrm{Y}=-2.674 \ln (\mathrm{x})+35.799$ & Logarithmic \\
\hline Walking & $\mathrm{Y}=2 \mathrm{E}-08 \mathrm{x} 2-0.0005 \mathrm{x}+12.27$ & Polynomial \\
\hline Public transport & $\mathrm{Y}=3 \mathrm{E}-05 \mathrm{x} 2-0.0457 \mathrm{x}+27.359$ & Polynomial \\
\hline
\end{tabular}

For model evaluation, 75 percent of the data are used to estimate the model and 25 percent are kept for the tested model. After obtaining the equation for 75 percent of the data, the estimated average intrazonal travel time is found for each zone. Then, to find the Performance Index (PI) for estimated and tested models, the average of the estimated average intrazonal travel time over observation is calculated for 75 percent and 25 percent of the data separately. Table 8 shows the PI for estimated and tested models for each mode. As much as the PI be near to 1, the accuracy of the model will be higher. 
Table 8 The Performance Index (PI) for estimated and tested models of intrazonal travel time.

\begin{tabular}{|l|l|l|}
\hline \multirow{2}{*}{ Model } & Performance Index (PI) \\
\cline { 2 - 3 } & Estimated model (0.75 Data) & Tested model (0.25 Data) \\
\hline All trip modes & 1.052 & 1.099 \\
\hline Walking & 1.061 & 1.086 \\
\hline Public transport & 1.171 & 1.178 \\
\hline
\end{tabular}

As it is presented in Table 8, the PI of the models is near to one, which shows that these models can estimate the average intrazonal travel time in the zone accurately.

The Figure 2, 3 and 4, shows the relation between the independent variable and average intrazonal travel time for each mode.

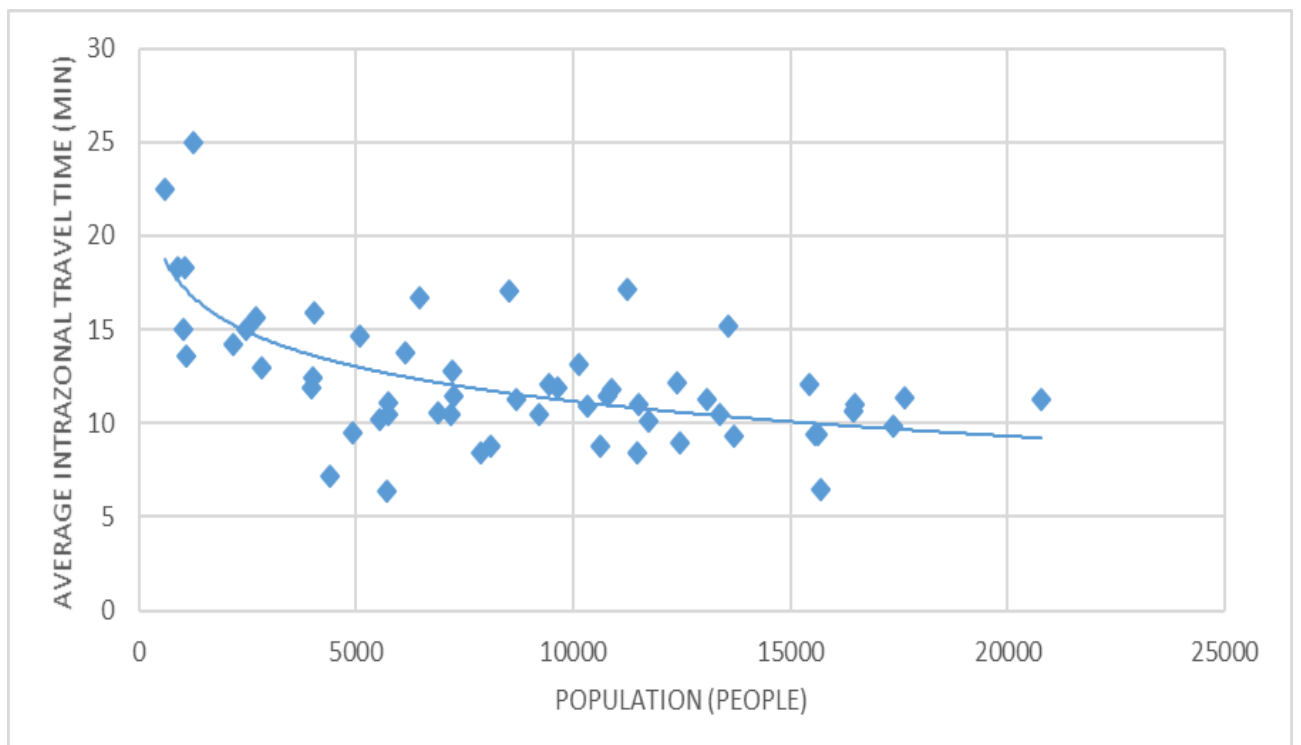

Figure 1: The relation between population and average intrazonal travel time for all trip modes. 


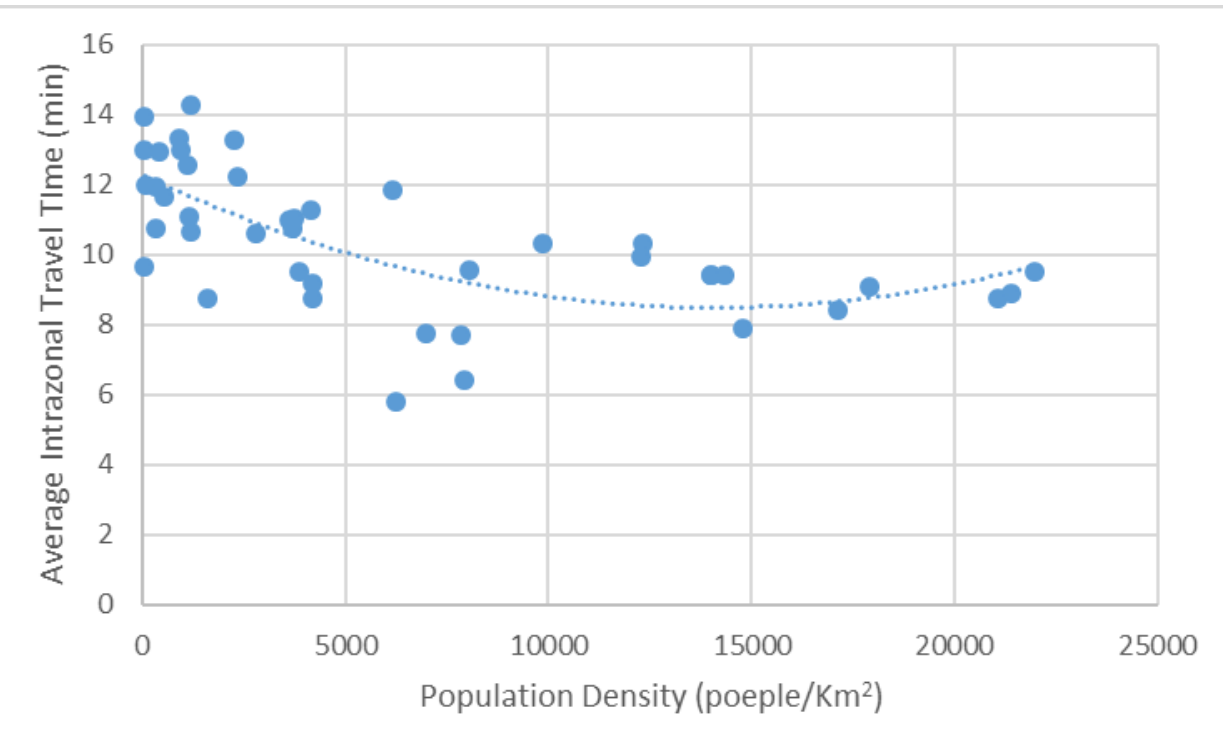

Figure 2: The relation between population density and average intrazonal travel time for walking trips.

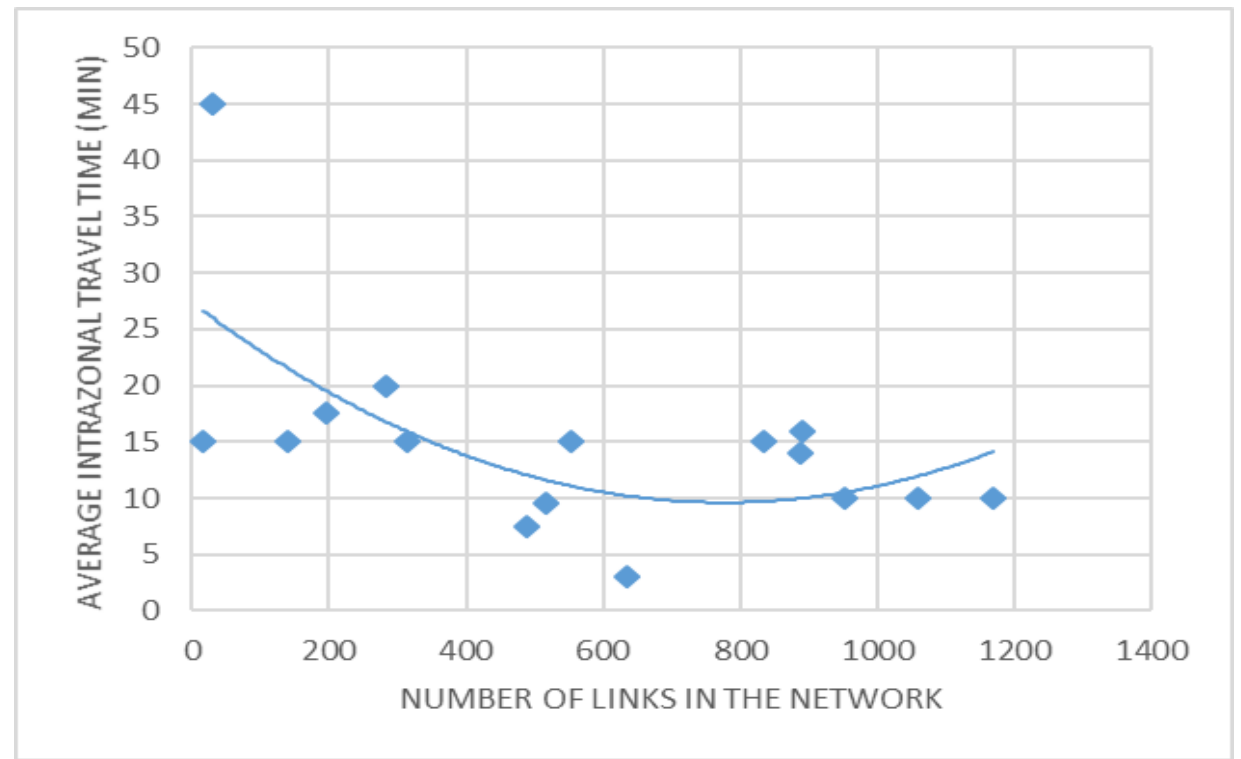

Figure 3: The relation between the number of links in the network and average intrazonal travel time for public transport trips.

For finding the points in which the data trends, regarding the related independent variable, has changed, the data is analyzed with testing different values as transition points for each model, which is shown in Table 9, 10 and 11. 
Table 9: the result of all trip modes model for the less and greater than or equal to values than the tested transition points.

\begin{tabular}{|l|c|c|}
\hline $\begin{array}{l}\text { Transition } \\
\text { point }\end{array}$ & $\begin{array}{l}\text { Equation for less values than } \\
\text { transition point }\end{array}$ & $\begin{array}{l}\text { Equation for greater than or euqal to values } \\
\text { than transition point }\end{array}$ \\
\hline 5000 & $\mathrm{y}=21.776 \mathrm{e}-2 \mathrm{E}-04 \mathrm{x}$ & $\mathrm{y}=-7 \mathrm{E}-10 \mathrm{x} 2-9 \mathrm{E}-05 \mathrm{x}$ \\
& $\mathrm{R}^{2}=0.587$ & +12.296 \\
& $\mathrm{R}=0.0317$ \\
\hline & $\mathrm{y}=2 \mathrm{E}-07 \mathrm{x}^{2}$ & $\mathrm{y}=4 \mathrm{E}-08 \mathrm{x}^{2}$ \\
10000 & $-0.0031 \mathrm{x}+21.326$ & $-0.0014 \mathrm{x}+21.53$ \\
& $\mathrm{R}^{2}=0.4901$ & $\mathrm{R}^{2}=0.0621$ \\
\hline & $\mathrm{y}=1 \mathrm{E}-07 \mathrm{x}^{2}$ & $\mathrm{y}=-8 \mathrm{E}-08 \mathrm{x}^{2}+0.0033 \mathrm{x}-21.69$ \\
15000 & $-0.0019 \mathrm{x}+19.506$ & $\mathrm{R}^{2}=0.1426$ \\
& $\mathrm{R}^{2}=0.4052$ & \\
\hline
\end{tabular}

Table 10: the result of the walking model for the less and greater than or equal to the values than the tested transition points.

\begin{tabular}{|c|c|c|}
\hline $\begin{array}{l}\text { Transition } \\
\text { point }\end{array}$ & $\begin{array}{l}\text { Equation for less values than } \\
\text { transition point }\end{array}$ & $\begin{array}{l}\text { Equation for greater than or equal to values } \\
\text { than transition point }\end{array}$ \\
\hline 5000 & $\begin{array}{c}\mathrm{y}=-2 \mathrm{E}-07 \mathrm{x}^{2} \\
+0.0003 \mathrm{x}+12.008 \\
\mathrm{R}^{2}=0.3047\end{array}$ & $\begin{array}{l}\mathrm{y}=3.2782 \times 0.1051 \\
\mathrm{R}^{2}=0.0693\end{array}$ \\
\hline 10000 & $\begin{array}{c}y=4 E-08 x^{2} \\
-0.0008 x+12.631 \\
R^{2}=0.4493\end{array}$ & $\begin{array}{c}y=5 E-08 x^{2}-0.0018 x+24.756 \\
R^{2}=0.5949\end{array}$ \\
\hline 15000 & $\begin{array}{c}\mathrm{y}=4 \mathrm{E}-08 \mathrm{x}^{2} \\
-0.0008 \mathrm{x}+12.596 \\
\mathrm{R}^{2}=0.4574\end{array}$ & $\begin{array}{c}y=3 E-08 x^{2}-0.0009 x+16.981 \\
R^{2}=0.3445\end{array}$ \\
\hline
\end{tabular}


Table 11: the result of the public transport model for the less and greater than or equal to values than the tested transition points.

\begin{tabular}{|c|c|c|}
\hline $\begin{array}{l}\text { Transition } \\
\text { point }\end{array}$ & $\begin{array}{l}\text { Equation for less values than } \\
\text { transition point }\end{array}$ & $\begin{array}{l}\text { Equation for greater than or equal to values } \\
\text { than transition point }\end{array}$ \\
\hline 200 & $\begin{array}{c}\mathrm{y}=-0.0768 \mathrm{x}+30.439 \\
\mathrm{R}^{2}=0.2042\end{array}$ & $\begin{array}{c}\mathrm{y}=2 \mathrm{E}-05 \mathrm{x} 2-0.0302 \mathrm{x}+22.78 \\
\mathrm{R}^{2}=0.1507\end{array}$ \\
\hline 400 & $\begin{array}{c}\mathrm{y}=0.0002 \mathrm{x} 2-0.1137 \mathrm{x} \\
+31.058 \\
\mathrm{R}^{2}=0.236\end{array}$ & $\begin{array}{c}\mathrm{y}=-3 \mathrm{E}-05 \mathrm{x} 2+0.0526 \mathrm{x}-9.9202 \\
\mathrm{R}^{2}=0.1575\end{array}$ \\
\hline 600 & $\begin{array}{c}\mathrm{y}=24.706 \mathrm{e}-0.002 \mathrm{x} \\
\mathrm{R}^{2}=0.4393\end{array}$ & $\begin{array}{c}\mathrm{y}=-1 \mathrm{E}-04 \mathrm{x} 2+0.1806 \mathrm{x}-71.456 \\
\mathrm{R}^{2}=0.6059\end{array}$ \\
\hline 800 & $\begin{array}{c}\mathrm{y}=28.304 \mathrm{e}-0.002 \mathrm{x} \\
\mathrm{R}^{2}=0.5708\end{array}$ & $\begin{array}{c}\mathrm{y}=0.0001 \mathrm{x} 2-0.2225 \mathrm{x}+130.77 \\
\mathrm{R}^{2}=0.7671\end{array}$ \\
\hline
\end{tabular}

The Table 9 to 11 show that the transition points regarding the R2 are 15000 people, 10000 people/area and 800 links in the network for all trip modes model, walking model and public transport model respectively.

\section{Conclusion:}

In this study, three different regression model is explored to estimate the average intrazonal travel time of three categorize of the modes including walking, public transport and the all trip modes together contains walking, private vehicle, public transport and subscription bus for home-based school trips. There different factors which affect the average intrazonal travel time are analyzed. For each model, the most related factor which has the highest correlation with the average intrazonal travel time is chosen to be used in the model as an independent variable, and the other factors are not put on the model because of having the high correlation with the selected factor. The selected significant factor for walking mode model is population density, for public transport mode is the number of links in the network and for all trip modes model is population. The results show that the best fit trend regarding the $\mathrm{R} 2$ for the walking mode and public transport is the polynomial trend line and for all trip, modes model is a logarithmic trend line. The 75 of data are used for model estimation and the rest used for testing the mode. The results demonstrate that these three models have an appropriate accuracy because of providing a proper PI, which is near to 1. Analysing the model by using different values for transition point, displays that the transition point, which shows the changing in the data trend regarding the independent variable, is 15000 people/area for all trip modes model, 10000 people for walking mode and 800 links in the network for public transport.

This study is focused on the estimating the intrazonal travel time of different mode categories in the medium-sized city for home-based school trips. In the future studies, the intrazonal travel time estimation for metropolitan cities and analyzing the effect of the size of the city on the intrazonal travel time can be studied. Moreover, models for the other modes such as private vehicle and subscription bus, cycling and other models for the different trip purposes such as home-based work, home-based other and none home-based trips can be provided. 


\section{References}

Angel, Shlomo, Jason Parent, and Daniel L. Civco. 2010. "Ten Compactness Properties of Circles: Measuring Shape in Geography." Canadian Geographer 54 (4): 441-61. https://doi.org/10.1111/j.1541-0064.2009.00304.x.

Batty, M., 1976. Urban Modeling: Algorithms, Calibrations, Predictions. Cambridge University Press, London.

Bhatta, Bharat P., and Odd I. Larsen. 2011. “Are Intrazonal Trips Ignorable?” Transport Policy 18 (1). Elsevier: 13-22. https://doi.org/10.1016/j.tranpol.2010.04.004.

Company, Learning. 2004. "University of California, Berkeley Urban Modelling: Algorithms, Calibrations, Predictions," no. c: 92-93.

Costa, Paula Teixeira da, José Fernando Gomes Mendes, Antônio Nélson Rodrigues da Silva. 1992. "An Analysis of Energy Consumption for Transportation In." 1992, 1-18.

Daganzo, Carlos F. 1984. "The Length of Tours in Zones of Different Shapes." Transportation Research Part B 18 (2): 135-45. https://doi.org/10.1016/0191-2615(84)90027-4.

Greenwald, Michael J. 2006. "The Relationship between Land Use and Intrazonal Trip Making Behaviors: Evidence and Implications." Transportation Research Part D: Transport and Environment 11 (6): 432-46. https://doi.org/10.1016/j.trd.2006.09.003.

"INTRAZONAL TRIP DISTANCES: AN ESTIMATION APPROACH AND APPLICATION TO A CASE STUDY Conrado Vidotte Plaza 1 Antônio Nélson Rodrigues Da Silva 2.” 2015, no. 1: $1-16$.

Khan, Mobashwir, Kara M. Kockelman, and Xiaoxia Xiong. 2014. "Models for Anticipating NonMotorized Travel Choices, and the Role of the Built Environment." Transport Policy 35. Elsevier: 117-26. https://doi.org/10.1016/j.tranpol.2014.05.008.

Kordi, M., C. Kaiser, and A. S. Fotheringham. 2012. A Possible Solution for the Centroidtocentroid and Intra-zonal Trip Length Problems. Proceedings of the AGILE' International Conference on Geographic Information Science, Avignon, April, 24-27, 2012.

Ortuzar, Juan de Dios, and Luis G. Willumsen. 2011. Modelling Transport. Modelling Transport. https://doi.org/10.1002/9781119993308.

Silva, Antônio Nélson Rodrigues da, Guilherme Camargo Ferraz Costa, and Nair Cristina Margarido Brondino. 2007. "Urban Sprawl and Energy Use for Transportation in the Largest Brazilian Cities." Energy for Sustainable Development 11 (3). International Energy Initiative, Inc.: 44-50. https://doi.org/10.1016/S0973-0826(08)60576-1.

Smeed, R J. 1967. “The Road Capacity of City Centers.” Highway Research Record 169 (1): 2229. http://onlinepubs.trb.org/Onlinepubs/hrr/1967/169/169003.pdf\%0Ahttp://trid.trb.org/view.aspx?id=134376.

Turner, Jeff. 2013. "Book Review." Journal of Transport Geography 29 (3): 106. https://doi.org/10.1016/j.jtrangeo.2013.01.007.

Venigalla, Mohan M., Arun Chatterjee, and Michael S. Bronzini. 1999. "A Specialized Equilibrium Assignment Algorithm for Air Quality Modeling." Transportation Research Part D: Transport and Environment 4 (1): 29-44. https://doi.org/10.1016/S1361-9209(98)00022-4. 